\title{
Influence of Vertical Ground Motions on the Seismic Fragility Modeling of a Bridge-Soil-Foundation System
}

\author{
Zhenghua Wang, ${ }^{\text {a) }}$ Jamie E. Padgett, ${ }^{\text {b) }}$ M.Eeri, and \\ Leonardo Dueñas-Osorio, ${ }^{c)}$ M.EERI
}

This paper explores the effects of vertical ground motions (VGMs) on the component fragility of a coupled bridged-soil-foundation (CBSF) system with liquefaction potential, and highlights the unique considerations on the demand and capacity model required for fragility analysis under VGMs. Optimal intensity measures (IMs) that account for VGMs are identified. Moreover, fragility curves that consider capacity change with fluctuating axial force are derived. Results show that the presence of VGMs has a minor effect on the failure probabilities of piles and expansion bearings, while it has a great influence on fixed bearings. Whether VGMs have an impact on column fragilities depends on the design axial load ratio. Finally, more accurate fragility surfaces are derived, which are compared with results of conventional fragility curves. This study highlights the important role that VGMs play in the selection of optimal IMs, and the capacity and fragility representation of certain components of CBSF systems. [DOI: 10.1193/1.4000170]

\section{INTRODUCTION}

Bridges are key components of transportation networks and play an important role in social and economic development. However, they are susceptible to damage under earthquakes especially in the presence of liquefiable soil. Therefore, seismic risk assessment is essential for adequately choosing appropriate design or retrofit measures to improve bridge response during earthquakes. Typical deterministic seismic analysis approaches are not able to account for inherent uncertainties associated with the seismic responses of bridges (Papazoglou and Elnashai 1996, Kim et al. 2011). In contrast, bridge fragility curves, which express the probability of a bridge reaching or exceeding a certain damage state for a given ground motion parameter (Mackie and Stojadinovic 2003, Nielson and DesRoches 2007a, 2007b), play an important role in seismic risk assessment and investment decision making.

Several researchers have studied the seismic fragility of bridges in the past using different levels of model sophistication. Nielson and DesRoches (2007a, 2007b) performed a comprehensive fragility analysis using nonlinear time-history analyses of several sophisticated bridge models with multiple damage mechanisms typical of central and eastern United States

\footnotetext{
a) Ph.D. Candidate, Department of Civil and Environmental Engineering, Rice University, Houston, TX 77005

b) Assistant Professor, Department of Civil and Environmental Engineering, Rice University, Houston, TX 77005

c) Assistant Professor, Department of Civil and Environmental Engineering, Rice University, Houston, TX 77005
} 
(CEUS) bridges, but the bridge foundations and soil material were modeled as lumped springs. Similarly, Mackie and Stojadinovic (2006) conducted fragility analyses using nonlinear time-history analysis on multi-span California highway bridges where bridge foundations were either fixed or modeled as springs. Zhang et al. (2008) efficiently evaluated the fragility of different bridge classes typical of California by considering soil liquefaction effects through an equivalent static analysis procedure. Recently, Pan et al. (2010) carried out fragility analyses to quantify improvements from retrofitting methods by comparing fragility curves and fragility surfaces of a typical multi-span simply supported steel bridge in the state of New York before and after different retrofit strategies with the foundations modeled as lumped springs. Kwon and Elnashai (2010) also developed fragility curves with a sophisticated bridge model including soil structure interaction (SSI) but excluding potential liquefaction effects.

Although previous work has contributed significantly to the enhancement of the fragility analysis of highway bridges, the effects of soil-pile interaction are accounted for in most papers through lumped springs whose properties are obtained from empirical data. However, the lumped spring approach cannot fully represent the complexity of soil behavior or the uncertainties associated with soil properties. In addition, most papers did not consider the liquefaction effect. Even in the recent studies that explicitly model SSI with liquefaction effect in the fragility analysis (Aygün et al. 2011), the results are incomplete in the sense that these studies neglect the influence of vertical ground motions (VGMs) on the seismic vulnerability of bridges. This highlights the need for bridge reliability assessment models that can explicitly account for SSI and VGMs while maintaining an acceptable computing time for probabilistic analyses.

Several publications have investigated the effect of VGMs on the seismic response of highway bridges. Both observational field bridge damage and time history analysis have shown that the inclusion of VGMs has a great influence on the seismic response, especially in the axial force demand of columns, which may lead to shear failure or yielding under bending moments that are much lower than the anticipated design capacity (Saadeghvariri and Foutch 1991, Papazoglou and Elnashai 1996, Kim et al. 2011). The vertical component of ground motion was also found to cause significant amplification in moment demands in girders at both the mid-span and the face of the bent cap (Veletzos et al. 2006, Kunnath et al. 2008). In particular, the amplification of negative moments in the mid-span section was found to exceed the capacity. Most of the mentioned studies are deterministic and focus on the response of the bridge decks and columns, while other key components sensitive to VGMs and load fluctuations (e.g., bridge bearings and piles) have not been explicitly modeled. In addition, little research has focused on the fragility analysis of CBSF systems under the combined effect of horizontal and vertical ground motions. Moreover, although probabilistic seismic demand models (PSDMs) are available in the literature for horizontal ground motions (HGMs), few studies have identified an optimal intensity measure (IM) which can display a good correlation with engineering demand parameters (EDPs) influenced the most by VGMs.

The purpose of this paper is to explore the effect of vertical ground motions on the fragility of key components of a coupled bridge-soil-foundation system (CBSF) considering soil heterogeneity and liquefaction potential. A fragility curve and fragility surface methodology is also presented to capture relevant IMs, along with its application to the chosen CBSF system 
via nonlinear time history analyses. The proposed methodology is demonstrated using a bridge type commonly found in the CEUS region. The main innovations of this study include:

1. The development of an efficient finite element model that can reasonably capture soil heterogeneity and liquefaction effects while accounting for VGMs and maintaining an acceptable computing time for fragility analyses.

2. The comparison of several ground motion IMs to identify an optimal metric for probabilistic seismic demand analysis in which the characteristics of VGMs are included. Then to improve the dispersions of PSDMs, optimal vector-valued IMs which include the characteristics of both HGMs and VGMs are also identified.

3. The development of capacity models for columns and piles that account for the capacity change with axial force variation. In previous studies, the structural capacity for a given limit state was assumed to be constant. However, the capacity of bridge columns and piles varies with different axial force levels and this is particularly important to consider because VGMs can generate significant axial force fluctuations in columns and piles. Neglecting capacity change with axial force fluctuation can have a great impact on the accuracy of component fragility estimates.

4. The identification of CBSF system components whose fragilities are sensitive or not to VGMs. In most published research, fragility curves for bridges only consider HGMs, which may underestimate the failure probability of the bridge components or system, especially in near fault regions where VGMs may have a great influence on the seismic response.

\section{MODELING APPROACH OF THE CBSF SYSTEM TO ACCOUNT FOR VGM EFFECTS}

A multi-span continuous steel (MSCS) girder bridge typical of the central and eastern United States (CEUS), and particularly the state of South Carolina (SC), is used to explore the effects of VGMs on the fragility analysis of the bridge and its key components. The elevation view of the chosen bridge with liquefiable soil profiles and cross section of several key components for this study is shown in Figure 1. Although the case study considers a representative MSCS bridge in the CEUS region, the finite element modeling strategy as well as the method to incorporate the effects of VGMs when assessing seismic fragility can be used to analyze other types of bridges in CEUS or other regions. The Open System for Earthquake Engineering Simulation (OpenSees) is used to perform the nonlinear dynamic analyses for the CBSF system. Detailed information on the CBSF modeling approach in OpenSees, including unique considerations in capturing the effect of VGMs, is presented by Wang et al. (2013), which uses a symmetric set of soil profiles and couples one-dimentional (1-D) $p-y, t-z$, and $q-z$ springs with two-dimensional (2-D) soils for keeping track of pore water pressures and the degradation of the soil stiffness after liquefaction and three-dimensional (3-D) bridge models. However, the present study accounts for the effect of soil heterogeneity by using asymmetric soil profiles with a reasonable number of soil layers as shown in Figure 1. This 1-D/2-D/3-D modeling strategy has been verified by the authors through the more complex and computationally intensive 2-D soil modeling approach considering different soil profiles. Comparatively, good results have been obtained for the non-liquefiable soils and liquefiable soils without lateral spreading or slope instability. The limitations of $1-\mathrm{D} / 2-\mathrm{D} / 3-\mathrm{D}$ models are 


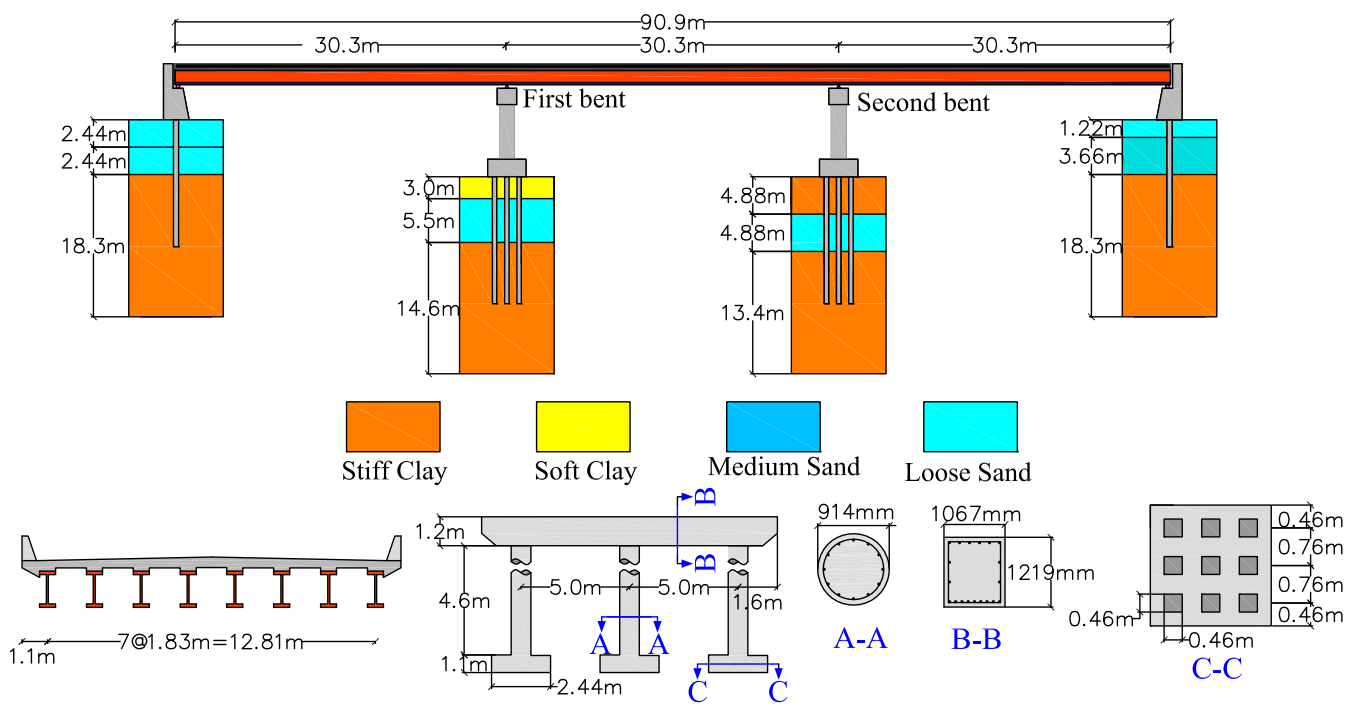

Figure 1. Layout of representative MSCS bridge for CEUS and South Carolina (modified from Wang et al. 2013).

that they cannot be used to simulate liquefaction-induced settlement, lateral spreading, and slope instability, which are beyond the scope of this study but are part of on-going research by the authors and others in the field. This 1-D/2-D/3-D modeling approach can capture SSI with liquefaction effects while maintaining an acceptable computing time compared to the sophisticated two-dimensional or three-dimensional soil foundation models. The 1-D/2-D/3-D modeling approach also provides the opportunity for probabilistic risk assessment of entire inventories of bridges and associated bridge networks.

\section{SELECTION OF INPUT GROUND MOTIONS}

Near-fault ground motions are generally characterized by both long-duration horizontal pulses and high-frequency motions in the vertical direction, with high values of the acceleration ratio $(P G A \mathrm{~V} / P G A \mathrm{H})$, defined as the ratio between the peak vertical acceleration, $P G A \mathrm{~V}$, and peak horizontal acceleration, $P G A \mathrm{H}$ (Mazza and Vulcano 2012). In this paper, a suite of 40 earthquake ground motion records at varying hazard levels are selected from the PEER strong motion database for adequate fragility analysis as listed in Table 1. These PEER records are used due to the scarcity of actual earthquake data or synthetic motions with vertical components in central and eastern United States. The records are all near-fault ground motions with closest distance less than $30 \mathrm{~km}$. Figure 2 shows the response spectra of the 40 ground motions in the horizontal direction and vertical directions along with the frequency histograms of the $P G A$ values, which demonstrates that the energy content of the VGM is mainly stored in the short periods. The $P G A \mathrm{H}$ varies greatly, ranging from a minimum value of $0.204 \mathrm{~g}$ to a maximum value of $1.779 \mathrm{~g}$. The nonlinear time history analyses of the CBSF system are carried out in two stages: at first, only horizontal components of the motion are applied, while in the second stage both horizontal and vertical components of the ground motions are applied simultaneously. In each analysis, critical 
Table 1. Input ground motions used for the response assessment of the CBSF system

\begin{tabular}{|c|c|c|c|c|c|c|c|c|}
\hline \multirow{2}{*}{$\begin{array}{l}\text { Earthquake } \\
\text { Name }\end{array}$} & \multirow[b]{2}{*}{ Station Name } & \multirow[b]{2}{*}{$\mathrm{M}_{\mathrm{w}}$} & \multirow{2}{*}{$\begin{array}{l}\text { Distance } \\
(\mathrm{km})\end{array}$} & PGA (g) & \multicolumn{2}{|c|}{$\begin{array}{c}\mathrm{PGV} \\
(\mathrm{cm} / \mathrm{sec})\end{array}$} & \multicolumn{2}{|c|}{ PGD $(\mathrm{cm})$} \\
\hline & & & & Horiz. Vert. & Horiz. & Vert. & Horiz. & Vert. \\
\hline Cape Mendocino & Cape Mendocino & 7.01 & 7.0 & 1.4970 .754 & 125.0 & 62.7 & 39.1 & 110.2 \\
\hline Cape Mendocino & Petrolia & 7.01 & 8.2 & 0.5900 .163 & 48.3 & 24.1 & 21.8 & 27.7 \\
\hline Cape Mendocino & Rio Dell Overpass - FF & 7.01 & 14.3 & 0.3850 .195 & 43.7 & 10.4 & 21.3 & 7.1 \\
\hline Chi-Chi, Taiwan & CHY028 & 7.62 & 3.6 & $0.653 \quad 0.337$ & 72.9 & 36.3 & 14.7 & 13.5 \\
\hline Chi-Chi, Taiwan & TCU080 & 6.30 & 10.2 & 0.4690 .480 & 28.7 & 11.9 & 5.6 & 2.3 \\
\hline Chi-Chi, Taiwan & CHY080 & 7.62 & 2.7 & 0.9680 .724 & 107.7 & 49.0 & 18.5 & 27.9 \\
\hline Chi-Chi, Taiwan & TCU065 & 7.62 & 0.6 & 0.8140 .272 & 126.2 & 77.0 & 92.7 & 53.8 \\
\hline Chi-Chi, Taiwan & TCU068 & 7.62 & 0.3 & 0.5660 .486 & 176.8 & 187.5 & 324.4 & 266.7 \\
\hline Chi-Chi, Taiwan & TCU071 & 7.62 & 5.3 & 0.5670 .449 & 44.5 & 34.8 & 13.7 & 31.2 \\
\hline Chi-Chi, Taiwan & TCU079 & 5.9 & 10.4 & 0.7430 .388 & 61.2 & 25.4 & 11.2 & 12.7 \\
\hline Chi-Chi, Taiwan & TCU084 & 7.62 & 11.2 & 1.1570 .340 & 114.8 & 25.4 & 31.5 & 11.9 \\
\hline Chi-Chi, Taiwan & TCU088 & 5.9 & 28.4 & 0.5080 .222 & 15.7 & 13.0 & 5.3 & 10.2 \\
\hline Coalinga & Pleasant Valley P.P. - yard & 6.36 & 8.4 & 0.5920 .353 & 60.2 & 16.0 & 8.9 & 2.3 \\
\hline Coalinga & Oil City & 5.77 & 8.5 & 0.2500 .098 & 9.4 & 3.0 & 0.8 & 0.3 \\
\hline Coalinga & Coalinga-14th \& Elm & 5.77 & 10.8 & 0.2040 .079 & 8.1 & 2.3 & 0.5 & 0.3 \\
\hline Coalinga & Transmitter Hill & 5.77 & 9.5 & 0.2050 .114 & 11.9 & 3.3 & 1.3 & 0.3 \\
\hline Duzce, Turkey & Bolu & 7.14 & 12.0 & $0.728 \quad 0.203$ & 56.4 & 17.3 & 23.1 & 14.2 \\
\hline Duzce, Turkey & Duzce & 7.14 & 6.6 & 0.3480 .357 & 59.9 & 22.6 & 42.2 & 19.3 \\
\hline Duzce, Turkey & Lamont 375 & 7.14 & 3.9 & 0.5140 .193 & 20.3 & 9.4 & 7.6 & 6.1 \\
\hline Imperial Valley & Agrarias & 6.53 & 0.7 & $0.370 \quad 0.835$ & 35.3 & 10.2 & 9.9 & 5.1 \\
\hline Imperial Valley & Bonds Corner & 6.53 & 2.7 & 0.5880 .425 & 45.2 & 12.2 & 16.8 & 4.1 \\
\hline Imperial Valley & El Centro Array \#5 & 6.53 & 4.0 & 0.5190 .537 & 47.0 & 38.4 & 35.6 & 19.8 \\
\hline Imperial Valley & El Centro Array \#6 & 6.53 & 1.4 & 0.4101 .655 & 64.8 & 57.2 & 27.7 & 25.4 \\
\hline Imperial Valley & El Centro Array \#7 & 6.53 & 0.6 & 0.3380 .544 & 47.5 & 26.4 & 24.6 & 9.4 \\
\hline Imperial Valley & El Centro Array \#8 & 5.01 & 11.0 & 0.6020 .439 & 54.4 & 22.4 & 32.5 & 11.9 \\
\hline Imperial Valley & El Centro Diff. Array & 6.53 & 5.1 & $0.352 \quad 0.707$ & 71.1 & 20.6 & 46.0 & 11.7 \\
\hline Imperial Valley & SAHOP Casa Flores & 6.53 & 9.6 & 0.2870 .379 & 19.3 & 9.1 & 2.5 & 1.3 \\
\hline Kobe, Japan & KJMA & 6.9 & 1.0 & 0.8210 .343 & 81.3 & 38.4 & 17.8 & 10.4 \\
\hline Kobe, Japan & Takarazuka & 6.9 & 0.3 & 0.6930 .433 & 68.3 & 34.8 & 26.7 & 12.4 \\
\hline Kobe, Japan & Takatori & 6.9 & 1.5 & 0.6110 .272 & 127.3 & 16.0 & 35.8 & 4.6 \\
\hline Kobe, Japan & KJMA & 6.9 & 1.0 & 0.8210 .343 & 81.3 & 38.4 & 17.8 & 10.4 \\
\hline Loma Prieta & Capitola & 6.93 & 15.2 & 0.5290 .541 & 35.1 & 17.8 & 9.1 & 2.8 \\
\hline Loma Prieta & Gilroy Array \#3 & 6.93 & 12.8 & 0.5550 .338 & 35.8 & 15.5 & 8.1 & 7.1 \\
\hline Loma Prieta & LGPC & 6.93 & 3.9 & 0.9660 .886 & 108.5 & 68.8 & 65.8 & 65.0 \\
\hline Loma Prieta & Saratoga - Aloha Ave & 6.93 & 8.5 & 0.5120 .389 & 41.1 & 26.9 & 16.3 & 15.2 \\
\hline Northridge & $\begin{array}{l}\text { Beverly Hills - } 12520 \\
\text { Mulhol }\end{array}$ & 6.69 & 18.4 & 0.6170 .314 & 40.6 & 14.0 & 8.6 & 1.3 \\
\hline Northridge & Castaic - Old Ridge Route & 6.69 & 20.4 & 0.5680 .217 & 51.8 & 12.4 & 8.9 & 5.6 \\
\hline Northridge & Pacoima Dam & 6.61 & 1.8 & 1.5851 .229 & 54.9 & 49.0 & 6.4 & 12.4 \\
\hline Northridge & Santa Monica City Hall & 6.69 & 26.5 & 0.8830 .230 & 41.7 & 14.2 & 14.7 & 4.6 \\
\hline Northridge & Simi Valley - Katherine Rd & 6.69 & 13.4 & 0.8770 .402 & 40.9 & 13.0 & 5.3 & 2.3 \\
\hline Northridge & Tarzana - Cedar Hill A & 6.69 & 15.6 & 1.7791 .048 & 109.7 & 73.4 & 33.0 & 22.4 \\
\hline
\end{tabular}




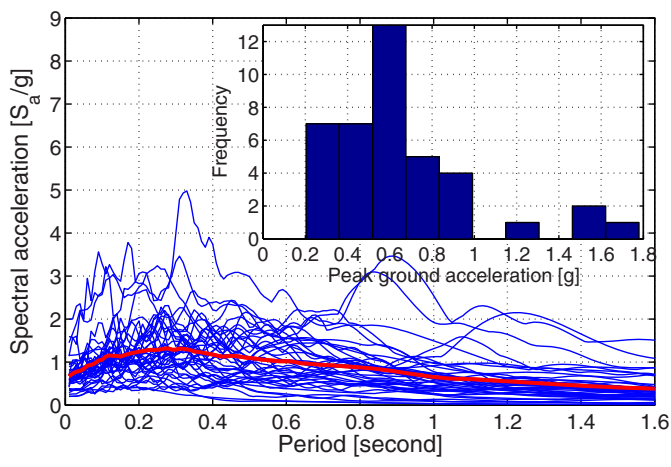

(a)

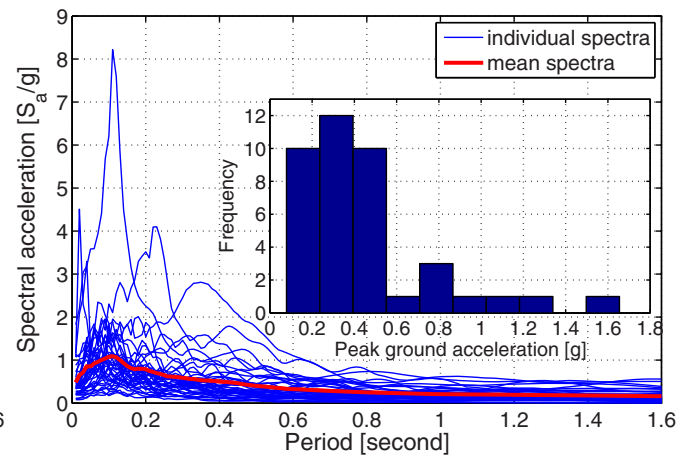

(b)

Figure 2. Spectral acceleration of the selected ground motions: (a) Horizontal ground motions; (b) vertical ground motions.

components' displacements and forces are monitored to gain an insight into the effects of vertical accelerations on the response of bridge structures.

\section{SELECTION OF THE OPTIMAL INTENSITY MEASURES THAT ACCOUNT FOR VGMS}

The ground motions are characterized by intensity measures (IMs) and their choice plays a crucial role in the fragility analysis of bridges. An optimal IM is one that has good efficiency, practicality, sufficiency, hazard computability, and predictability among other characteristics (Mackie and Stojadinovi 2001, Giovenale et al. 2004, Padgett et al. 2008). Several studies have investigated the effects of using different IMs, such as $P G A, P G V$, spectral acceleration, and others (Mackie and Stojadinovic 2003, Padgett et al. 2008, Bradley et al. 2009, Shafieezadeh et al. 2012). So far, most researchers have adopted $P G A$ and spectral acceleration at the fundamental period as the ground motion intensity measure when assessing the fragility of bridges. However, most studies did not consider VGMs in determining optimal IMs. In addition, previous studies have shown that $P G A$ is not an ideal IM for evaluating liquefaction because it cannot consider the duration of the ground motions (Kramer et al. 2008). Determining the optimum IM is still a challenge especially for coupled bridge-soil-foundation (CBSF) systems when liquefaction is considered. One of the objectives of this study is to identify an optimal IM for the seismic response of CBSF systems under the combined effect of vertical and horizontal ground motions.

\section{INTRODUCTION OF PROBABILISTIC SEISMIC DEMAND MODELS (PSDMs)}

A PSDM offers a relationship between peak demands on a structure and the ground motion IM. Cornell et al. (2002) proposed that the median seismic demand on steel frame buildings approximately follows a power law, which is a function of the value of the chosen IM. This model Equation 1 has also been widely adopted for bridges, particularly under horizontal-only ground motions:

$$
S_{D}=a I M^{b}
$$


This expression can be rearranged to perform a linear regression of the logarithms of the IM and response quantity to establish a demand of the following form:

$$
\ln \left(S_{D}\right)=b \cdot \ln (I M)+\ln (a)
$$

where $S_{D}$ is the median value of structural demand, and $a$ and $b$ are regression coefficients.

Different ground motion parameters should be used as IMs depending on the governing response characteristics of the structure considered. Since the seismic response of a CBSF system is complex, especially when VGMs are considered, it is necessary to examine a wide range of potential IMs and identify the optimum IM for the prediction of bridge response.

The engineering demand parameters (EDPs) considered for the development of PSDMs herein were selected among the structural response parameters that were most significantly influenced by the inclusion of VGMs. Results from prior studies (Saadeghvariri and Foutch 1991, Button et al. 2002, Kunnath et al. 2008, Kim et al. 2011, Wang et al. 2013) showed that the following EDPs are impacted significantly by VGMs: the bending moment demand at the middle of the end span, at the center of the bridge, and at the bents; the axial force of the columns, which will have an effect on the flexural and shear capacity of the columns; and the normal force of the bearings that in turn affects their force displacement relationship. Although VGMs do not have a great impact on the seismic demand of the pile cap displacement and the maximum axial force of the piles, it may have some influence on the pile capacity due to the pile axial force variation. Regarding bridge deck bending moments, the flexural capacity of the girders in the positive direction is adequate to resist the increase in the demands due to the VGMs. However, the amplification of the moment demand in the negative direction may exceed the capacity, especially for deck moments at the center of the end span. In terms of the columns, their axial force demands are not a concern since they do not exceed their axial capacity, although the significant fluctuation of axial forces has a great impact on the poorly confined columns' shear and flexural capacity. However, the decrease of shear capacity due to the axial load fluctuation is not expected to cause the failure of the columns as their design and behavior is flexure dominated even if axial load fluctuations are considered (Wang et al. 2013). For the bearings, the significant fluctuations of the normal force may have a great impact on the seismic demand on the bearings. Therefore, PSDMs are developed for the columns, piles, negative deck bending moment at the middle of the end span, and the expansion and fixed bearings.

For the columns and the piles, whose capacities are changing with the axial force demand caused by the VGMs, the peak values of the drift ratio and the pile cap displacement do not necessarily occur at the most critical axial load demand. Therefore, the time histories of the column drift ratio and the pile cap displacement are divided by the capacities at the corresponding axial load for each analysis time step to get demand-capacity ratios and monitor the maximum level. For the bridge deck and the bearings, the maximum demand-capacity ratio occurs at the same time step with the maximum demand since their capacities for different limit states are constant.

When scalar IMs are adopted for the demand modeling, only one IM can be chosen to depict the ground motion characteristic. Hence, PSDMs are built to explore optimal IMs for components that are influenced by both horizontal and vertical ground motions. Either IMs from the horizontal motions or IMs from the vertical motions are considered, depending upon the 
dominant influence of ground motion component on the bridge component behavior. For example, analysis of results show that the negative bending moments of the deck at the middle of the end span are mainly caused by the VGMs and can be decoupled from the HGMs. This conclusion is in line with the results obtained by Kunnath et al. (2008). Therefore, the optimal IM for the negative deck bending moment should be obtained from the VGMs. The maximum axial force of the columns and the maximum normal force of the bearings are also mainly influenced by VGMs. Although the normal force variations of the bearings can affect the stability of the steel bearings or cause the pullout of the bolt, this type of failure of the bearings is not well understood and additional tests are needed to verify the failure of the bearings caused by normal force variation coupled with lateral load. Therefore, this study mainly focuses on the influence of significant variations of the normal force on the mechanism of the load transfer through the bearing. For instance, if normal forces are zero or tensile, the lateral frictional force transferred from the bridge deck to the bearing will reduce substantially. The bearing model used in this study can update the normal force at every time step automatically to account for the change of the frictional horizontal force transferred from the deck (Wang et al. 2013). Hence, the axial force of the columns and normal forces of bearings are chosen as EDPs in order to check which IMs from VGMs are optimal for EDPs that are mainly affected by VGMs. As listed in Table 2,

Table 2. Intensity measures to characterize input ground motions

\begin{tabular}{|c|c|c|c|c|}
\hline IM & Description & Units & HGMs & VGMs \\
\hline$P G A$ & Peak ground acceleration & $\mathrm{g}$ & $\mathrm{x}$ & $\mathrm{x}$ \\
\hline$P G V$ & Peak ground velocity & $\mathrm{cm} / \mathrm{sec}$ & $\mathrm{x}$ & $\mathrm{x}$ \\
\hline$P G D$ & Peak ground displacement & $\mathrm{cm}$ & $\mathrm{x}$ & $\mathrm{x}$ \\
\hline$V S I$ & Velocity spectrum intensity & $\mathrm{cm}$ & $\mathrm{x}$ & $\mathrm{x}$ \\
\hline Arias & Arias intensity & $\mathrm{cm} / \mathrm{sec}$ & $\mathrm{x}$ & $\mathrm{x}$ \\
\hline$R m s A$ & Root mean square acceleration & $\mathrm{g}$ & $\mathrm{x}$ & $\mathrm{x}$ \\
\hline$C A V$ & Cumulative absolute velocity & $\mathrm{cm} / \mathrm{sec}$ & $\mathrm{x}$ & $\mathrm{x}$ \\
\hline$C A D$ & Cumulative absolute displacement & $\mathrm{cm}$ & $\mathrm{x}$ & $\mathrm{x}$ \\
\hline Bracket & Bracketed duration & $\sec$ & $\mathrm{x}$ & $\mathrm{x}$ \\
\hline Duration & Duration of the ground motion & $\sec$ & $\mathrm{x}$ & $\mathrm{x}$ \\
\hline$S_{a-n o n l i n e r}$ & $\begin{array}{l}\text { Spectral acceleration at the nonlinear horizontal fundamental } \\
\text { period }\end{array}$ & $\mathrm{g}$ & $\mathrm{x}$ & \\
\hline$S_{d-n o n l i n e a r}$ & $\begin{array}{l}\text { Spectral displacement at the nonlinear horizontal fundamental } \\
\text { period }\end{array}$ & $\mathrm{g}$ & $\mathrm{x}$ & \\
\hline$S_{a-e l a s t i c}$ & Spectral acceleration at elastic horizontal fundamental period & $\mathrm{g}$ & $\mathrm{x}$ & \\
\hline$S_{\text {a-eadd }}$ & $\begin{array}{l}\text { Geometrical mean of the spectral acceleration at the elastic and } \\
\text { nonlinear horizontal fundamental period }\end{array}$ & $g$ & $\mathrm{x}$ & \\
\hline$S_{a 1}$ & Spectral acceleration at the period of the first vertical mode & g & & $\mathrm{x}$ \\
\hline$S_{a 2}$ & Spectral acceleration at the period of the second vertical mode & $\mathrm{g}$ & & $\mathrm{x}$ \\
\hline$S_{a 12-G M}$ & $\begin{array}{l}\text { Geometrical means of spectral acceleration at first and second } \\
\text { vertical periods }\end{array}$ & $\mathrm{g}$ & & $\mathrm{x}$ \\
\hline$S_{a 12-S R S S}$ & $\begin{array}{l}\text { Square-root-of-the-sum-of-squares (SRSS) of spectral } \\
\text { acceleration at first and second vertical periods }\end{array}$ & $\mathrm{g}$ & & $\mathrm{x}$ \\
\hline
\end{tabular}

Note: IMs from either HGMs or VGMs or both are indicated by "x"; for example, $P G A$ is used to describe both horizontal $P G A$ and vertical $P G A$, whereas $\mathrm{S}_{\mathrm{a} 1}$ is used to describe the spectral acceleration of the vertical ground motion at the period of the first vertical mode. 
a total of 14 different IMs from HGMs are considered for the column drift, pile cap displacement and bearing displacement, which are dominated by HGMs and also influenced by VGMs. Another 14 different IMs from VGMs are also considered for the negative deck bending moment, maximum axial force of columns, and maximum normal force of fixed bearings. Table 2 indicates if the IM is considered for the HGM, VGM, or both. The first ten IMs are evaluated for both the HGMs and VGMs. The choice of these IMs is mainly based on the literature review and prior deterministic analyses by the authors (Wang et al. 2013).

\section{NONLINEAR TIME HISTORY ANALYSIS WITH LATIN HYPERCUBE SAMPLING}

There are inherent uncertainties associated with the seismic responses of the CBSF system due to either ground motions or soil structure interaction (e.g., structural properties, soil properties, liquefaction mechanism, ground movement, etc.) The uncertainties in the structural and geotechnical model such as concrete and steel strengths, bearing friction coefficients, damping ratio, gap between deck and abutment, soil density, and cohesion and friction angles of the foundation soil are all treated as random variables whose specific probability distributions are based on literature reviews (Nielson 2005, Aygun et al. 2011, Zhang 2006, Nielson and DesRoches 2007) and compiled in Table 3. Using a Latin-hypercube sampling technique (Ayyub and Lai 1989), 40 bridge models are generated accounting for the epistemic uncertainty in material properties, component behaviors and damping, each of which is subjected to one of the chosen ground motions. After each nonlinear time history analysis, the maximum demand/ capacity ratios or the maximum demands are recorded, and regression analyses are carried out to establish the relationship between the EDPs and the IMs for different components.

\section{OPTIMAL IMS THAT ACCOUNT FOR VGMS FOR KEY COMPONENTS OF THE CBSF SYSTEM}

An efficient IM reduces the amount of variation in the estimated demand for a given IM value (Giovenale et al. 2004). Employing an efficient IM yields less dispersion about the estimated median in the results of the nonlinear time history analysis, which is captured in this study by low values of $\beta_{D \mid \mathrm{IM}}$, and estimated by Equation 3 (Padgett et al. 2008):

$$
\beta_{D \mid \mathrm{IM}}=\sqrt{\frac{\sum\left(\ln \left(S_{D i}\right)-\ln \left(a I M^{b}\right)\right)^{2}}{N-2}}
$$

Practicality refers to whether or not there is any direct correlation between an IM and the demand placed on the structure. If an IM is not practical, there is little or no dependence of the level of structural demand upon the level of the IM. Practicality is measured by the regression parameter $b$ in the PSDM. Proficiency measures the composite effect of practicality and efficiency. A more proficient IM has a lower modified dispersion, $\zeta$, which is an indication of the uncertainty introduced into the analysis by use of a particular IM. The proficiency is defined as (Padgett et al. 2008):

$$
\zeta=\frac{\beta_{D \mid \mathrm{IM}}}{b}
$$


Table 3. Probability distributions and associated parameters for CBSF system modeling

\begin{tabular}{|c|c|c|c|c|c|c|c|c|}
\hline \multirow[b]{2}{*}{ Random Parameters } & \multirow{2}{*}{$\begin{array}{l}\text { Probability } \\
\text { Distribution }\end{array}$} & \multicolumn{6}{|c|}{ Assumed Distribution Parameters } & \multirow[b]{2}{*}{ Ref. } \\
\hline & & $\mu^{2}$ & $\sigma^{3}$ & $\lambda^{4}$ & $\xi^{5}$ & $\mathrm{COV}^{6}$ & Bounds & \\
\hline Concrete strength (MPa) & Normal & 33.8 & 4.3 & - & - & - & - & $*$ \\
\hline Steel strength (MPa) & Lognormal & - & - & 6.13 & 0.08 & - & - & $*$ \\
\hline $\begin{array}{l}\text { Coefficient of friction }(\mathrm{COF}) \\
\text { for expansion bearing }\left(\mathrm{L}^{1}\right)\end{array}$ & Lognormal & - & - & -3.22 & 0.5 & - & - & $*$ \\
\hline COF for fixed bearing $\left(\mathrm{L}^{1}\right)$ & Lognormal & - & - & -1.56 & 0.5 & - & - & $*$ \\
\hline $\begin{array}{l}\text { Initial stiffness of fixed } \\
\text { bearing }(\mathrm{kN} / \mathrm{m})\end{array}$ & Uniform & - & - & - & - & - & $0.5-1.5$ & $*$ \\
\hline $\begin{array}{l}\text { Rayleigh damping (mass and } \\
\text { stiffness proportional) }\end{array}$ & Normal & - & - & - & - & 0.28 & - & $*$ \\
\hline Gap at the left abutment (m) & Normal & 7.62 & - & - & - & 0.32 & - & $*$ \\
\hline Gap at the right abutment (m) & Normal & 7.62 & - & - & - & 0.32 & - & $*$ \\
\hline $\begin{array}{l}\text { Passive abutment resistance } \\
(\mathrm{kN} / \mathrm{m})\end{array}$ & Uniform & - & - & - & - & - & $11.5-28.8$ & $*$ \\
\hline Ground motion & Uniform & - & - & - & - & - & $1-40$ & - \\
\hline Shear modulus $(\mathrm{kPa})$ & Lognormal & - & - & $\mathrm{x}$ & - & 0.30 & - & $\begin{array}{c}\text { Aygun } \\
\text { et al. } \\
\text { (2011) }\end{array}$ \\
\hline Undrained shear strength $(\mathrm{kPa})$ & Lognormal & - & - & $\mathrm{x}$ & - & 0.22 & - & $\begin{array}{l}\text { Zhang } \\
(2006)\end{array}$ \\
\hline Friction angle & Normal & $\mathrm{x}$ & - & - & - & 0.12 & - & $\begin{array}{l}\text { Zhang } \\
(2006)\end{array}$ \\
\hline Soil density (ton/m³) & Lognormal & - & - & $\mathrm{x}$ & - & 0.1 & & $\begin{array}{l}\text { Zhang } \\
(2006)\end{array}$ \\
\hline Contraction parameter & Normal & $\mathrm{x}$ & - & - & - & 0.2 & - & $\begin{array}{c}\text { Aygun } \\
\text { et al. } \\
(2011)\end{array}$ \\
\hline
\end{tabular}

*Nielson (2005), Nielson and DesRoches (2007)

${ }^{1} \mathrm{~L}$-longtudinal direction; ${ }^{2} \mu$-mean; ${ }^{3} \lambda$-logarithmic mean; ${ }^{4} \sigma$-standard deviation; ${ }^{5} \xi$-logarithmic standard deviation; ${ }^{6} \mathrm{COV}$-coefficient of variation;

$\mathrm{x}$ : Parameters with only a COV reported have different mean values depending upon soil type.

Before exploring the IM effects on PSDMs, key bridge components are chosen for detailed analyses. The results of the nonlinear time history analysis for the CBSF system show that columns in the second bent have larger drift ratios than columns in the first bent for most of the 40 cases analyzed. Hence, columns in the second bent have higher risk of damage and are chosen for fragility analyses. Although fragility analysis of the piles at all locations are conducted, the results also show that the piles at the second bent are the most vulnerable and hence selected. The reason that columns and piles at the second bent are more vulnerable is that the crust layer above the liqeufiable layer at the second bent is stiff clay while the crust layer at the first bent is soft clay. Compared to soft clay, stiff clay can provide more resistence and associated demands to the pile and columns when liquefaction occurs. Results indicate that liquefaction occurs for most of ground motions considered. Several studies have investigated 
the effect of liquefaction on the horizontal seismic response of bridges under HGMs (Ledezma 2007, Zhang et al. 2008). However, the effect of liquefaction on the vertical seismic response of bridges under VGMs was not considered in these prior studies. The liquefaction effect on the seismic response of the chosen CBSF system under HGMs has been studied by Aygün et al. (2011), who showed that liquefaction tended to increase the displacement of the expansion and fixed bearings while liquefaction reduced the curvature ductility of the column. The authors (Wang et al. 2013) have investigated the influcence of liquefaction on the vertical seismic response of the CBSF system and obtained several general conclusions. Regarding the columns, the results showed that liquefaction also tends to reduce their axial force fluctuations (Wang et al. 2013). In addition, the influence of liquefaction on the vertical seismic response can be either beneficial or detrimental depending on the frequency content of the individual motions and their relation to the dynamic properties of the CBSF system. The results herein capture such effects of liquefaction on horizontal and vertical seismic behavior when evaluating the fragility of the CBSF system.

Table 4 lists the top four scalar IMs for HGMs based on their overall efficiency, practicality and proficiency for the column drift, pile cap displacement and bearing displacement for the complete damage states, which are influenced by both HGMs and VGMs. The IMs are listed in increasing order of efficiency. For other damage states, the conclusions are the same as for the complete damage state. Table 4 shows that $P G D$ is the most efficient IM for the columns and piles but $P G D$ is not good for the expansion bearings and fixed bearings, and is not even in the list of the top four IMs. $P G V$ and $V S I$ are good for all of the components and $P G V$ is repeatedly better than VSI. Based on the proficiency values given in

Table 4. Demand models and horizontal IM comparisons for key bridge components influenced by both HGMs and VGMs

\begin{tabular}{llccccc}
\hline \hline \multirow{2}{*}{ EDP } & Top IM & & & & & \\
& from HGMs & $\ln (a)$ & $b$ & $R^{2}$ & $\beta$ & $\zeta$ \\
\hline Column drift demand-capacity ratio & $P G D$ & -3.4516 & 0.7975 & 0.7501 & 0.5733 & 0.7188 \\
& $C A D$ & -6.1067 & 0.9194 & 0.6998 & 0.6353 & 0.6910 \\
& $P G V$ & -6.5376 & 1.3305 & 0.6797 & 0.6561 & 0.4931 \\
& $V S I$ & -6.2518 & 0.9491 & 0.5933 & 0.6800 & 0.7165 \\
Pile cap displacement & $P G D$ & -1.5668 & 0.8305 & 0.9016 & 0.3372 & 0.4060 \\
demand-capacity ratio & $P G V$ & -4.8167 & 1.4056 & 0.8827 & 0.3682 & 0.2619 \\
& $C A D$ & -4.2271 & 0.9452 & 0.8606 & 0.4014 & 0.4246 \\
& VSI & -4.8068 & 1.0641 & 0.8224 & 0.4279 & 0.4022 \\
Expansion-bearing displacement & $P G V$ & -4.1320 & 0.9316 & 0.8584 & 0.2707 & 0.2906 \\
demand-capacity ratio & VSI & -4.3285 & 0.7460 & 0.8249 & 0.2971 & 0.3982 \\
& $C A D$ & -3.6696 & 0.6085 & 0.8174 & 0.3033 & 0.4985 \\
Fixed-bearing displacement & $S_{\text {a-nonlinear }}$ & 0.2096 & 0.6185 & 0.7836 & 0.3302 & 0.5340 \\
demand-capacity ratio & $S_{\text {a-eaddp }}$ & -3.6262 & 1.2046 & 0.7273 & 0.6097 & 0.5062 \\
& VSI & -10.2712 & 1.1552 & 0.6724 & 0.6970 & 0.6033 \\
& $P G V$ & -9.6597 & 1.3552 & 0.6393 & 0.7313 & 0.5397 \\
& Arias & -6.0181 & 0.7961 & 0.6067 & 0.7535 & 0.9464 \\
\hline \hline
\end{tabular}


Table 4, $P G V$ is the best IM for the CBSF system, and also consistently ranks among the top IMs on the basis of efficiency across all components. Figure 3 illustrates the PSDM in the lognormally transformed space and parameters estimated from the regression for $P G V$. It can be seen from the figure that for the piles and expansion bearings, the PSDM using the scalar IM from HGMs is very good, despite the potential impact of VGMs on the component demands. However, for the columns and the fixed bearings, the scalar IM from HGMs alone cannot predict the seismic demand as accurately given the significant influence of both HGMs and VGMs on component behavior. These results are also reflected by the coefficient of determination from the probabilistic seismic demand analysis. These deficient PSDMs using scalar IMs from HGMs can be improved with vector-valued IMs that combine vertical and horizontal ground motion IMs, which will be discussed in a later section.

Table 5 presents the parameters establishing PSDM functional relationships of the negative deck bending moment, the maximum axial force of the columns and the normal force of the bearings, which are influenced mainly by VGMs. In this table, the top four IMs from the vertical ground motions are presented. It can be seen that the Arias intensity is the most efficient IM for the negative bending moment, followed by $S_{a 12-S R S S}$. When considering

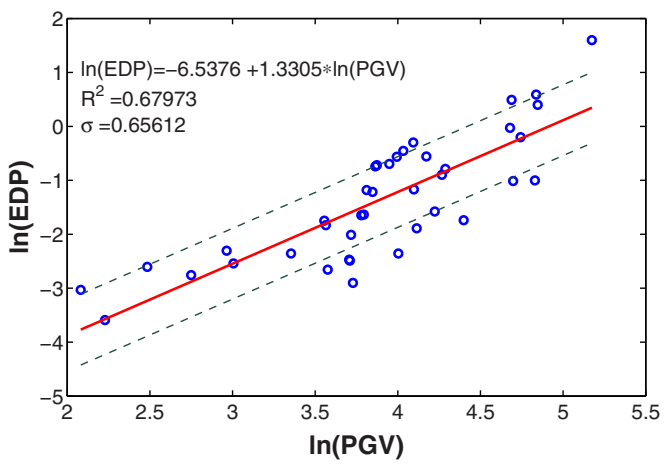

(a)

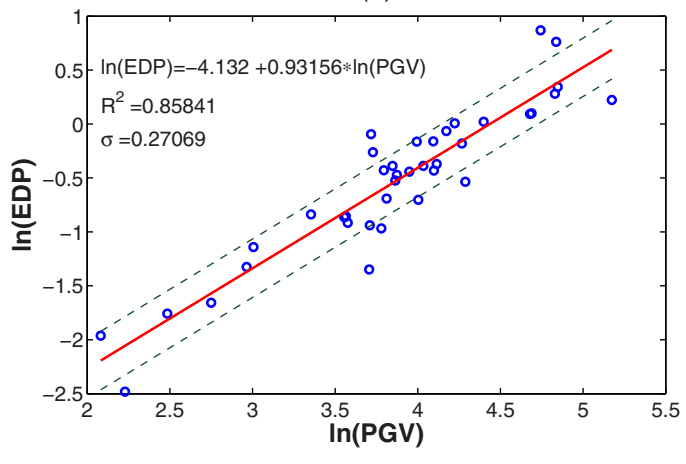

(c)

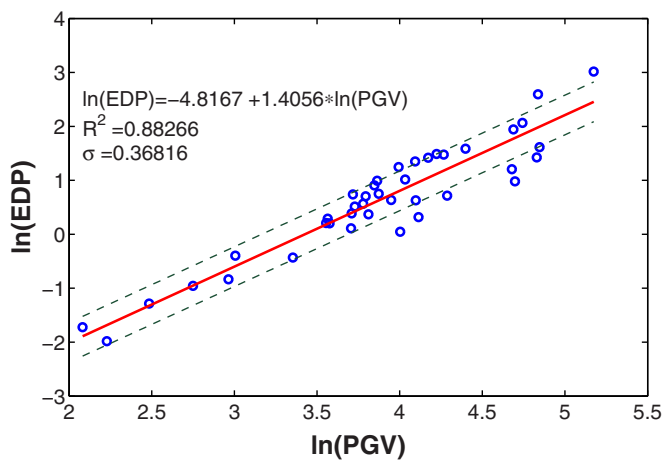

(b)

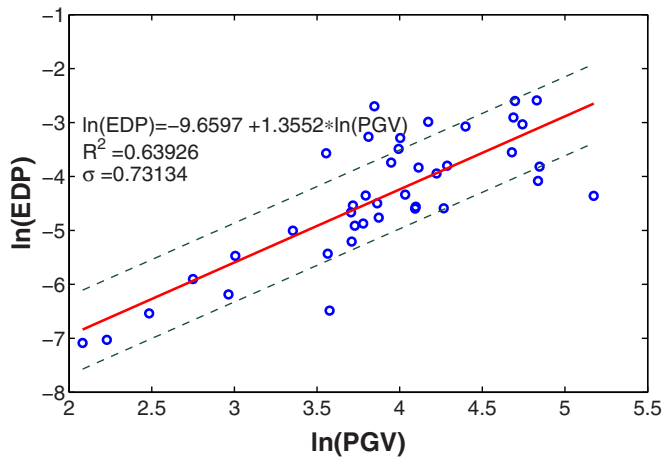

(d)

Figure 3. Probabilistic seismic demand model given PGV for demand-capacity ratio: (a) Columns; (b) piles; (c) expansion bearings; (d) fixed bearings. 
Table 5. Demand models and IM comparisons for the key components that are mainly sensitive to VGMs

\begin{tabular}{llccccc}
\hline \hline \multirow{2}{*}{ EDP } & $\begin{array}{l}\text { Top IM } \\
\text { from VGMs }\end{array}$ & $\ln (a)$ & $b$ & $R^{2}$ & $\beta$ & $\zeta$ \\
\hline Bridge deck negative bending & Arias & 0.0043 & 0.5175 & 0.7707 & 0.3413 & 0.6595 \\
moment demand-capacity ratio & $S_{a 12-S R S S}$ & 0.1410 & 0.9843 & 0.7753 & 0.3424 & 0.3479 \\
& $S_{a 2}$ & 0.3871 & 0.9621 & 0.7668 & 0.3487 & 0.3625 \\
& $S_{a 12-G M}$ & 0.5264 & 0.9670 & 0.7415 & 0.3672 & 0.3797 \\
Column axial force & $S_{a 2}$ & 7.6990 & 0.2174 & 0.7693 & 0.0747 & 0.3435 \\
& $S_{a 12-S R S S}$ & 7.6345 & 0.2222 & 0.6951 & 0.0906 & 0.4076 \\
& $S_{a 12-G M}$ & 7.7191 & 0.2153 & 0.6509 & 0.0969 & 0.4504 \\
Normal force of fixed bearing & Arias & 7.5987 & 0.1086 & 0.5825 & 0.1058 & 0.9743 \\
& $S_{a 2}$ & 6.6026 & 0.2040 & 0.6539 & 0.0919 & 0.4502 \\
& $S_{a 12-S R S S}$ & 6.5485 & 0.2000 & 0.6215 & 0.0961 & 0.4803 \\
& $S_{a 12-G M}$ & 6.6245 & 0.1935 & 0.5806 & 0.1011 & 0.5227 \\
& Arias & 6.5068 & 0.0891 & 0.4622 & 0.1145 & 1.2847 \\
\hline \hline
\end{tabular}

the composite effect of practicality and efficiency, $S_{a 12-S R S S}$ is superior. For the axial force of the columns and the normal force of the fixed bearings, $S_{a 2}$ is the best IM from the perspective of efficiency and proficiency, followed by $S_{a 12-S R S S}$. However, $S_{a 2}$ may be specific to this case study and not generalizable. Therefore, more generalizable $S_{a 12-S R S S}$ which combines the characteristics of spectral accelerations at the first and second periods is recommended as the optimal IM for the EDPs that are caused mainly by VGMs. Moreover, the results show that the spectral acceleration at the second vertical mode of the bridge deck is more efficient than spectral acceleration at the fundamental vertical mode. This differs from the horizontal only vibration case when the spectral acceleration at the fundamental period of the structures is often used as a good IM to predict the seismic response of structures. A better correlation between the negative deck moment and $S_{a 12-S R S S}$ is observed, and this can be explained by the significant contribution of higher modes (mode 2) in the vertical direction response of the bridge. This phenomenon has been observed by the authors (Wang et al. 2013) through the Fourier spectra of the acceleration of the bridge deck from the presence of several peaks corresponding to the first few vertical natural frequencies of the bridge. Regarding the mass participation of such vertical motions, analyses reveal that the mass participation of the first vertical mode is $15 \%$ and the mass participation of the second vertical mode is $36 \%$ for the case study bridge. These results indicate that the second vertical mode plays an important role in the vertical seismic response, and highlight the need for higher mode inclusion in the response analyses (Wang et al. 2013). Figure 4 illustrates the PSDM in the lognormally transformed space and parameters estimated from the regression for $S_{a 12-S R S S}$. It can be seen from these figures that the dispersions are very small, therefore a scalar IM of $S_{a 12-S R S S}$ from VGMs alone can predict the seismic demand well for the deck negative bending moment demand-capacity ratio, column axial force, and fixed bearing normal force. 


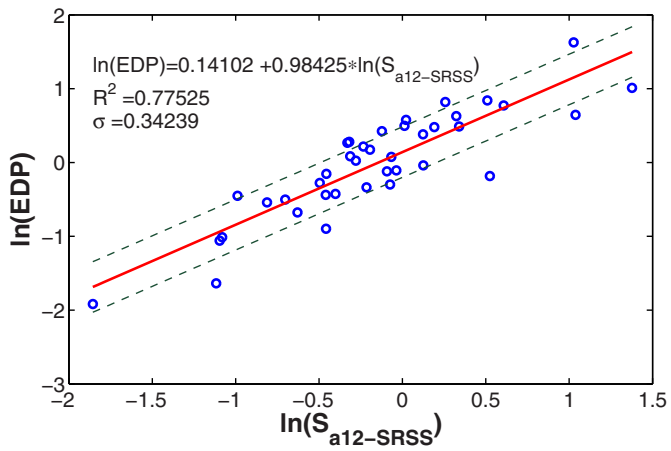

(a)

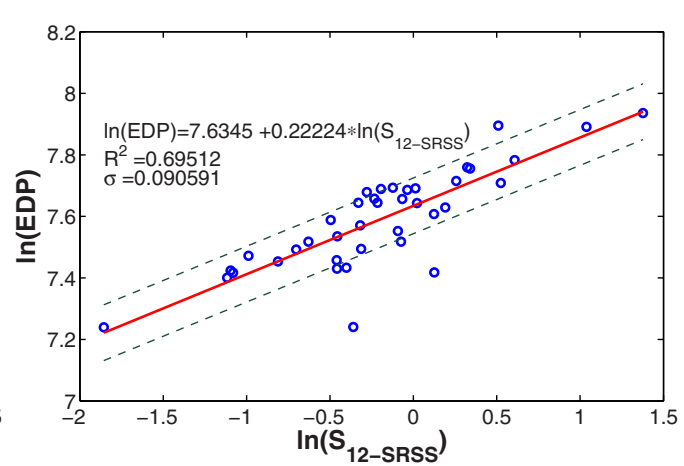

(b)

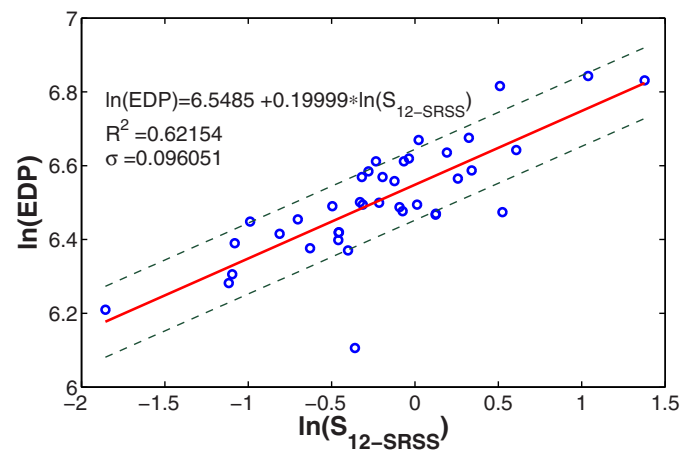

(c)

Figure 4. Probabilistic seismic demand model of PGV for: (a) Bridge deck bending moment demand-capacity ratio; (b) axial force of columns; (c) normal force of fixed bearings.

\section{SEISMIC FRAGILITY ANALYSIS FOR KEY COMPONENTS OF THE CBSF SYSTEM}

Fragility curves capture the conditional probability of a structure to reach or exceed predefined damage states given an IM. If both the demand and the capacity of the structural components are assumed to follow a lognormal distribution, the conditional probability can be defined as:

$$
P\left[\frac{D}{C} \geq 1 \mid \mathrm{IM}\right]=\Phi\left(\frac{\ln \left(\frac{S_{D}}{S_{C}}\right)}{\sqrt{\beta_{D / C}^{2}+\beta_{C}^{2}}}\right)
$$

where $\Phi(\cdot)$ is the standard normal cumulative distribution function; $D$ is the structural demand; $C$ is the structural capacity; $S_{C}$ is the median value of structural capacity; $\beta_{D / C}$ is the logarithmic standard deviation of the demand-capacity ratio; and $\beta_{C}$ is the logarithmic standard deviation of the capacity. The probabilistic models for the seismic demands are obtained from the PSDM analysis in the previous section. If capacities are estimated for 
each bridge component, then fragility curves can be generated using Equation 5. The capacities for the components will be discussed in following section.

\section{LIMIT STATES FOR THE FRAGILITY ANALYSIS}

Limit states for bridge components combine a qualitative description of their level of damage and associated traffic closure times with a quantitative metric of their physical state Nielson and DesRoches 2007). Often four damage states_-slight, moderate, extensive, and complete - are defined for the fragility analysis of bridges. The capacity limit states associated with each damage state can be described by the median values and the dispersions for the selected limit states of various bridge components. In addition, for the columns and the piles, the capacity change with the fluctuation of axial force induced by VGMs should be considered. A summary of the capacity limit states for each damage state of key CBSF components is shown in Table 6, and the following sections provide descriptions of the limit states adopted including unique considerations when the structure is subjected to VGMs.

\section{COLUMNS}

There are a number of different measures that are available for defining the limit states of reinforced concrete columns. These metrics include drift ratio, displacement ductility, residual displacement, and curvature ductility, among others. In this study, the drift ratio is adopted as the EDP for columns. The drift ratio is defined as the ratio of relative displacement between the top and the base of the bridge piers to their height. Several values for the drift collapse limit state have been suggested in the literature and in seismic codes. However, most of them neglect the influence of the variations of the axial force on the limit states of column. Berry and Eberhard (2003) developed empirical equations to estimate deformations at bar buckling and cover concrete spalling based on theoretically expected trends in drift ratios considering the axial force of the columns. The bar-buckling equation coefficients were

Table 6. Limit states for select components of the CBSF system

\begin{tabular}{|c|c|c|c|c|c|c|c|c|c|}
\hline \multirow[b]{2}{*}{$\begin{array}{l}\text { Bridge } \\
\text { component }\end{array}$} & \multirow[b]{2}{*}{$\begin{array}{l}\text { Monitored component } \\
\text { response }\end{array}$} & \multicolumn{2}{|c|}{$\begin{array}{l}\text { Slight } \\
\text { damage }\end{array}$} & \multicolumn{2}{|c|}{$\begin{array}{l}\text { Moderate } \\
\text { damage }\end{array}$} & \multicolumn{2}{|c|}{$\begin{array}{l}\text { Extensive } \\
\text { damage }\end{array}$} & \multicolumn{2}{|c|}{$\begin{array}{l}\text { Complete } \\
\text { damage }\end{array}$} \\
\hline & & $\begin{array}{c}\text { Med } \\
\left(S_{c}\right)\end{array}$ & $\begin{array}{r}\text { Disp } \\
\left(\beta_{c}\right)\end{array}$ & $\begin{array}{l}\text { Med } \\
\left(S_{c}\right)\end{array}$ & $\begin{array}{c}\text { Disp } \\
\left(\beta_{c}\right)\end{array}$ & $\begin{array}{c}\text { Med } \\
\left(S_{c}\right)\end{array}$ & $\begin{array}{c}\text { Disp } \\
\left(\beta_{c}\right)\end{array}$ & $\begin{array}{l}\text { Med } \\
\left(S_{c}\right)\end{array}$ & $\begin{array}{l}\text { Disp } \\
\left(\beta_{c}\right)\end{array}$ \\
\hline Column failure & Drift ratio & 0.0076 & 0.3 & Eq. $6^{\#}$ & 0.35 & $2 / 3 \times$ Eq. 7 & 0.24 & Eq. $7^{\#}$ & 0.24 \\
\hline Pile failure & $\begin{array}{l}\text { Pile cap } \\
\text { displacement (m) }\end{array}$ & Eq. 8 & 0.3 & Eq. 9 & 0.3 & Eq. 10 & 0.5 & Eq. 11 & 0.5 \\
\hline $\begin{array}{l}\text { Fixed bearing } \\
\text { failure }(*)\end{array}$ & $\begin{array}{l}\text { Longitudinal displacement } \\
(\mathrm{mm})\end{array}$ & 6.0 & 0.25 & 20.0 & 0.25 & 40.0 & 0.47 & 186.6 & 0.65 \\
\hline $\begin{array}{l}\text { Expansion bearing } \\
\text { failure }(*)\end{array}$ & $\begin{array}{l}\text { Longitudinal displacement } \\
(\mathrm{mm})\end{array}$ & 34.4 & 0.60 & 104.2 & 0.55 & 136.1 & 0.59 & 186.6 & 0.65 \\
\hline Deck failure & $\begin{array}{l}\text { Negative bending } \\
\text { moment }(\mathrm{kN}-\mathrm{M})\end{array}$ & - & - & - & - & - & - & 5,000 & 0.5 \\
\hline
\end{tabular}

*Nielson (2005), Nielson and DesRoches (2007), ${ }^{\#}$ Berry and Eberhard (2003, 2005)

Med: Median value; Disp: Dispersion; Eq.: Equation 
modified in Berry and Eberhard (2005). The resulting equations for the drift ratio at the onset of cover spalling and bar buckling are provided below in Equations 6 and 7, respectively:

$$
\begin{gathered}
\frac{\Delta_{s p}}{L}(\%)=1.6\left(1-\frac{P}{A_{g} f_{c}^{\prime}}\right)\left(1+\frac{L}{10 D}\right) \\
\frac{\Delta_{b b}}{L}(\%)=3.25\left(1+K_{e \_b b} \rho_{e f f} \frac{d_{b}}{D}\right)\left(1-\frac{P}{A_{g} f_{c}^{\prime}}\right)\left(1+\frac{L}{10 D}\right)
\end{gathered}
$$

where $\Delta_{s p}$ is the column relative displacement at the onset of cover spalling; $\Delta_{b b}$ is the column relative displacement at the onset of bar buckling; $K_{e-b b}=40$ for rectangular-reinforced columns and 150 for circular columns; $\rho_{\text {eff }}=\rho_{s} f_{y s} / f_{c}^{\prime}, \rho_{s}=$ volumetric transverse reinforcement ratio; $f_{y s}=$ yield stress of the transverse reinforcement; $d_{b}=$ diameter of the longitudinal reinforcing steel; $P=$ axial load, $A_{g}=$ gross area of the cross section; $f_{c}^{\prime}=$ concrete compressive strength; $L=$ distance from the column base to the point of contraflexure; and $D=$ column depth. The ratios of the measured displacements at cover spalling $\Delta_{s p}$ to the displacements calculated with the proposed model had a mean of 1.07 for spiral-reinforced columns with a coefficient of variation (COV) of 35\% (Berry and Eberhard 2003). The ratios of the measured displacements at bar buckling $\Delta_{b b}$ to the displacements calculated with the proposed model had a mean of 0.97 and a COV of $24 \%$ for spiral-reinforced columns (Berry and Eberhard 2005). Bar bucking corresponds to the complete damage state herein and cover spalling corresponds to the moderate damage state based on the damage process of reinforced concrete columns. Capacities for slight and extensive damage states that consider the change of axial force are still lacking. This paper uses the yield of the reinforcement and two thirds of the displacement at the bar bucking as the slight and extensive damage state, respectively.

\section{PILES}

Pile cap displacements are often used to quantify pile damage because they can be easily computed (Ledezma 2007) and are easier than other metrics to observe in the field to assess pile foundation integrity and performance (Aygün et al. 2011). It has also been found that the peak lateral pile cap displacement correlated well with the peak curvature of the pile (Bradley et al. 2009). However, traditional limit states for piles, if considered in fragility analyses, are assumed constant during the seismic excitation without considering any axial force variations. In this study, pile limit states are established from pushover analyses in OpenSees accounting for lateral soil pile interaction. Different levels of axial force in the piles are analyzed to evaluate the change in capacity as a function of axial load. First yield, second yield, two thirds of ultimate, and ultimate curvatures of the piles are adopted to capture slight, moderate, extensive, and complete damage states, respectively. These levels of curvature are related to the lateral pile cap displacement from the pushover analyses. This SSI analysis is needed because pile limit states are a function of not only their design, but also the soil profiles in which they are embedded. Regression of the limit state capacities, measured as pile cap displacements, versus axial force is conducted based on the least square method. Results show that a quadratic regression between the pile cap displacement and axial force is adequate, with a coefficient of determination of the regression larger than 0.95 . The resulting equations for pile cap displacements in centimeters $(\mathrm{cm})$ at the second bent for the four 
damage states are provided below. For the first yield damage state, the influence of axial force variations is negligible and a constant value is adopted:

$$
\begin{gathered}
\Delta_{s}=2.15 \\
\Delta_{m}=2.949 e^{-7} P^{2}-4.669 e^{-4} P+3.14 \\
\Delta_{e}=2.153 e^{-7} P^{2}-2.962 e^{-4} P+8.11 \\
\Delta_{c}=3.228 e^{-7} P^{2}-4.4401 e^{-4} P+12.16
\end{gathered}
$$

where $\Delta_{s}$ is the pile cap displacement capacity for slight damage, $\Delta_{m}$ for moderate damage; $\Delta_{e}$ for extensive damage, $\Delta_{c}$ for complete damage, and $P(\mathrm{kN})$ is the axial force of the pile (positive for compression). Results from structural analysis under low intensity ground motion have lower variability than results under high intensity ground motions (Kwon et al. 2007). Therefore, this paper assumes a coefficient of variation of 0.25 for slight and moderate damage states and 0.5 for extensive and complete damage states for the piles (and bridge deck) based on the authors' judgment and literature review.

\section{BEARINGS}

The damage states of high-type steel bearings are usually determined based on experimental data. Typically, the bearing displacement is used to describe the damage states. The median values and dispersions of the prescriptive limit states previously used in the work by Nielson (2005) are used in this study as listed in Table 6. These limit states values are based on the tests by Mander et al. (1996). The influence of normal force variations coupled with lateral load on the capacity of the bearings is not well understood and requires future study, including additional testing to verify the influence of normal force on the limit state capacity of the high type steel fixed and expansion bearings considered.

\section{BRIDGE DECK}

Little research has focused on the limit states of the bridge deck because the deck is typically expected to remain linearly elastic under seismic loading. However, this may not be the case for the bridge subjected to VGMs. Since the composite bridge deck has a limited negative bending capacity, the moment demand may exceed the capacity in the negative direction when VGMs are considered, especially for deck moments at the center of the end span (Wang et al. 2013). In this paper, only the complete damage state of the bridge deck corresponding to the bending moment that causes the upper concrete reach the tensile strength is adopted based on the section properties of the deck.

\section{COMPONENT FRAGILITY CURVES OF THE CBSF SYSTEM}

Figure 5 compares the fragility curves for the columns, the piles, the expansion bearings and the fixed bearings with the effect of VGMs $(H \& V)$ and without them $(H)$. These fragility curves use $P G V$ as the optimal IM identified in above section. It can be seen that the VGMs do not have any influence on the fragility of the pile. Additionally, the results for the columns 


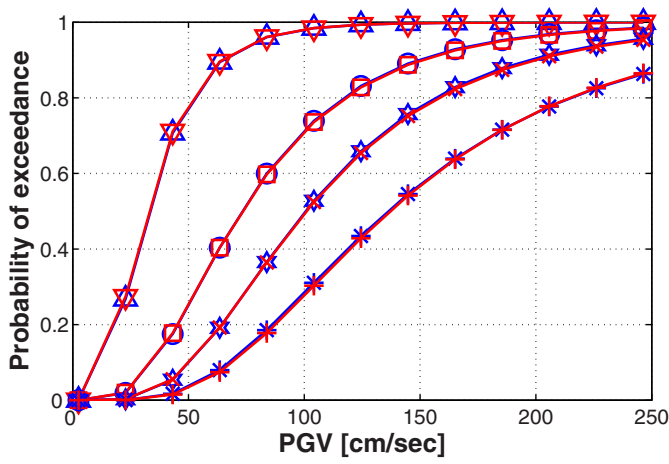

(a)

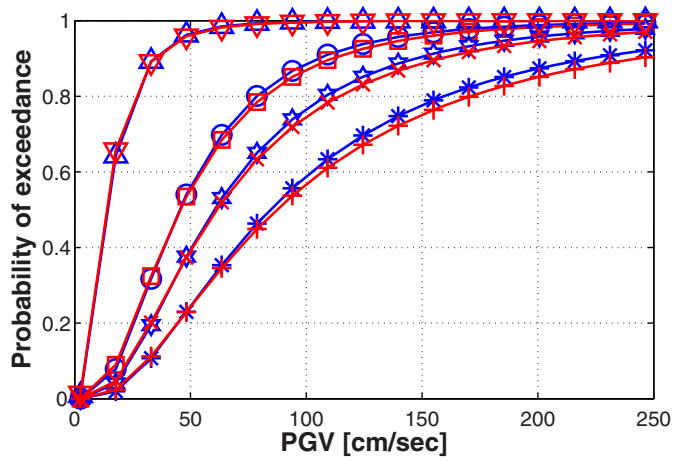

(c)

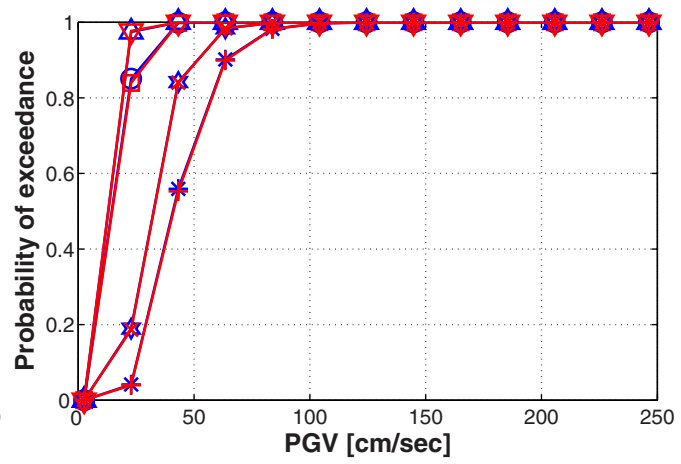

(b)

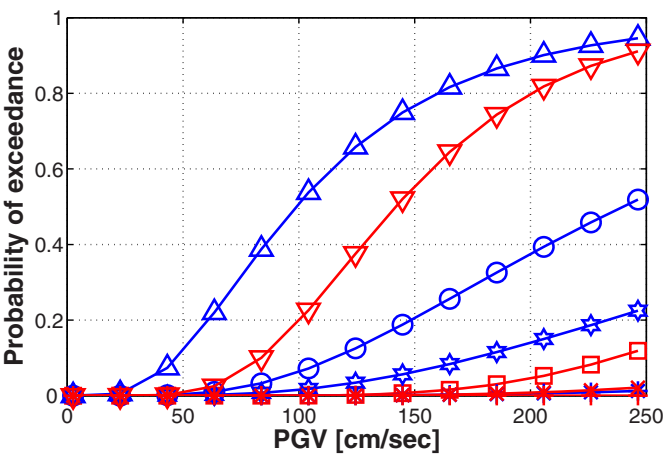

(d)

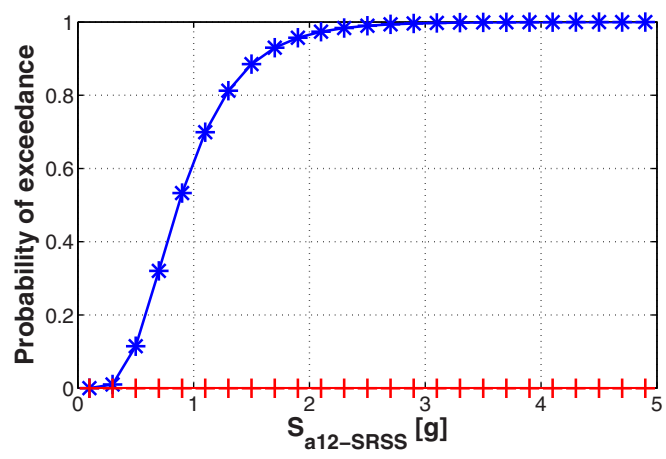

(e)

Figure 5. Fragility curves for (a) columns; (b) piles; (c) expansion bearings; (d) fixed bearings; (e) bridge deck.

reveal a surprising lack of impact of VGMs on their fragility, despite the significant influence of VGMs on the axial force of the column. In fact, it is found that whether VGMs will have impact on the fragility of the columns depends on the configuration of the column, specifically the initial design axial load ratio of the columns. From Equations 6 and 7, it can be seen how the axial force influences the column capacity, which is dominated by the axial load ratio term $-P / A_{g} f_{c}^{\prime}$. For example, as Elnashai and Papazoglou (1997) also showed 
previously, VGMs can have a significant impact on the column axial load ratio, potentially resulting in tensile forces on the columns.

Figure 6 shows the axial load ratio time history of the column of the chosen CBSF system with and without VGMs for the Pacoima Dam, Northridge earthquake - a large earthquake with $P G A \mathrm{H}=0.968 \mathrm{~g}$ and $P G A \mathrm{~V}=0.724 \mathrm{~g}$. The initial design axial load ratio of the column is approximately 0.05 . It can be seen from Figure 6 that even for such a large earthquake, the peak axial load axial ratio changes less than $5 \%$ for the $H \& V$ case compared with the $H$ case. This explains why VGMs do not have any influence on the fragility of the column. Figure 6 also shows another axial load ratio time history of a hypothetical column with initial design axial load ratio of 0.15 . The analysis reveals that if the design axial load ratio increases from 0.05 to 0.15 , the peak axial load ratio changes more than $15 \%$ for the $H \& V$ case compared with the $H$ case. Continued increases in the design axial load ratio also result in a continued increase in the percent variation in axial load ratio from dynamic analysis for the $H \& V$ case compared with the $H$ case. For the piles, the maximum and minimum axial force of the pile is not significantly influenced by the VGMs because the axial forces of the piles are dominated by the rocking of the foundation and the superstructure caused by the horizontal ground motions.

For the expansion bearings, the fragilities at the slight and moderate damage states are similar with and without vertical ground motions, but begin to deviate for the extensive and complete damage states with $P G V$ s corresponding to the median fragility increased by $2 \%$ and $4 \%$ for the extensive and complete damage states, respectively. However, the fragility curves for the fixed bearings are significantly influenced by the VGMs compared to the expansion bearings for the four limit states. For instance, the $P G V \mathrm{~s}$ corresponding to the median value of the fragility increase by $43 \%$ for the slight damage state of the fixed bearings. The reason that VGMs have more impact on the fixed bearings is that VGMs cause significant fluctuations of normal forces on the bearings and the fixed bearings carry more vertical loads, almost three times as much as the expansion bearings. For the bridge deck, there is no negative bending moment generated under the horizontal-only excitations, which

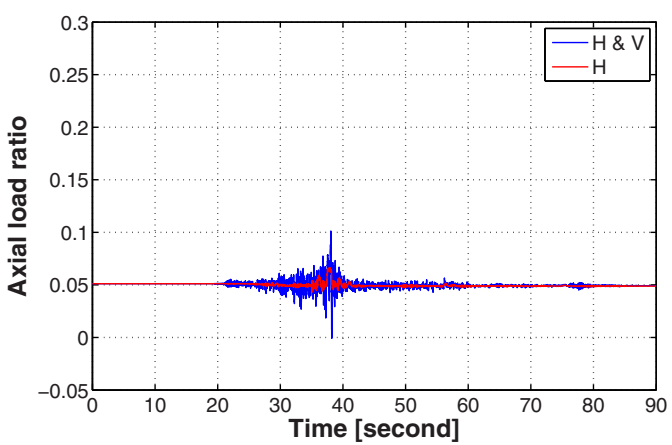

(a)

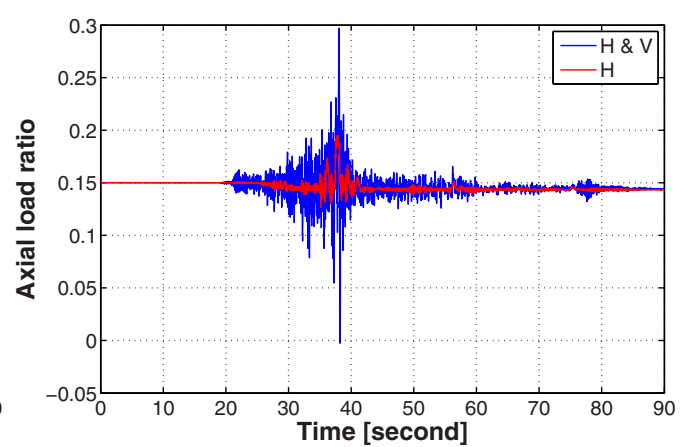

(b)

Figure 6. Influence of VGMs on the axial load ratio of the bridge columns: (a) Original section with design axial load ratio of 0.05 ; (b) hypothetical section with design axial load ratio of 0.15 . 
means that without VGMs the bridge deck has basically zero failure probability in the negative direction. The median $S_{a 12-S R S S}$ for the complete damage of the bridge deck is $0.869 \mathrm{~g}$. For near fault ground motions, this value is plausible. Therefore, the effects of VGMs should be more explicitly considered in the design and analysis of the bridge deck, especially for bridges located in near fault regions. These figures demonstrate the need to include the VGMs in estimating bridge fragilities for the fixed bearings, the columns with large initial design axial load ratio and the bridge deck.

\section{FRAGILITY SURFACE FOR COMPONENTS OF THE CBSF SYSTEM}

From the results of component fragility curves, it can be seen that because only a single IM from the HGMs is used for the components influenced by both HGMs and VGMs, the dispersion for some components (e.g., the fixed bearing) is large. Since the response of structures can depend on both HGMs and VGMs, using vector IMs allows for more accurate predictions of the response by using more complete descriptions of the scenarios (Kunnath et al. 2008). Therefore, vector-valued IMs are used to predict the seismic demand of the components that have large dispersions. While probabilistic seismic demand analysis using scalar IMs is a well-developed concept, incorporation of vector-valued IMs remains a challenging task. This is in part because there are many different parameters that can be adopted as vector-valued IMs and also because the appropriate form of the demand model for vector valued IMs with vertical ground motions is yet to be defined. Fourteen IMs from the HGMs and VGMs (Table 2) are used. Hence, a total of all possible 196 IM pairs are considered to build the relationship between the seismic demand and the IM pairs. Multivariate regression analysis is conducted to develop PSDMs as a natural extension from Equation 2:

$$
\ln \left(S_{D}\right)=a \cdot \ln \left(I M_{1}\right)+b \cdot \ln \left(I M_{2}\right)+\mathrm{c} .
$$

where $S_{D}$ is the structural demand, and $a, b$, and $c$ are regression coefficients. The fragility surfaces for each limit state can still be computed using Equation 5.

The results of the fragility curves confirm that the dispersions of the fixed bearing are very large using only a scalar IM from HGMs, and that the influence of VGMs on the fragility of the fixed bearing is significant. Although the dispersion of the columns is also large, the influence of VGMs on the column fragility of the chosen CBSF system is negligible, which means trying to improve the dispersion of the column by adding IMs from VGMs is not practical. However, this does not mean that other vector-valued IMs from HGMs will not improve the dispersion of column EDPs, which is beyond the scope of this study. The dispersions of other components are already relatively low, so in this section, only the fixed bearing is chosen to test the vector-valued IMs including vertical IMs and to construct fragility surfaces.

After comparing the 196 IM pairs, the combination of VSI (from HGMs) and $S_{a 2}$ (from VGMs) gives the smallest dispersion 0.5595 for the complete damage state for the fixed bearings. The horizontal IM and vertical IM vectors of $V S I$ and $S_{a 12-S R S S}, P G V$ and $S_{a 2 \text {, }}$ and $P G V$ and $S_{a 12-S R S S}$ also give dispersions less than 0.6 while scalar IM gives a dispersion of 0.73 . These results are quite reasonable as can be seen from the PSDM analyses that VSI and $P G V$ are good IMs from the HGMs and $S_{a 2}$ and $S_{a 12-S R S S}$ are good IMs from VGMs. Again, $S_{a 2}$ is not recommended as explained above, and the combination of VSI and $S_{a 12-S R S S}$ is 
recommended instead. The dispersion decreases by $22 \%$ for the multivariate regression using VSI and $S_{a 12-S R S S}$ compared to the regression using $P G V$ alone. The coefficient of determination increases from 0.639 to 0.78 . For other damage states, the trends are the similar to the complete damage state. Hence, vector-valued IMs can predict the seismic demand better, which means that fragility surfaces can improve estimates of fragilities relative to fragility curves derived solely as functions of a single IM.

Figure 7 shows the fragility surface of the fixed bearings for the four limit states. It is observed that the fragility of the fixed bearings is high for the slight damage. However, there is very small probability of complete damage. This result is consistent with the results of the $P G V$ fragility curve.

By comparing the response of the fixed bearings from the results of fragility surfaces and fragility curves, it is possible to assess to what extent fragility surfaces improve the seismic vulnerability analysis. Figure 8 compares the results of the failure probability obtained from the fragility surface and fragility curve for the four limit states. The figure shows multiple slices of the fragility surface with $S_{a 12-S R S S}$ increasing from $0.2 \mathrm{~g}$ to $2.6 \mathrm{~g}$, in increments of $0.4 \mathrm{~g}$. Figure 8 also shows the failure probability estimated from the fragility surface for each of the 40 earthquakes considered in this paper. It is observed that fragility curves lie between the slices of the fragility surface with different $S_{a 12-S R S S}$ values for different limit states. For the

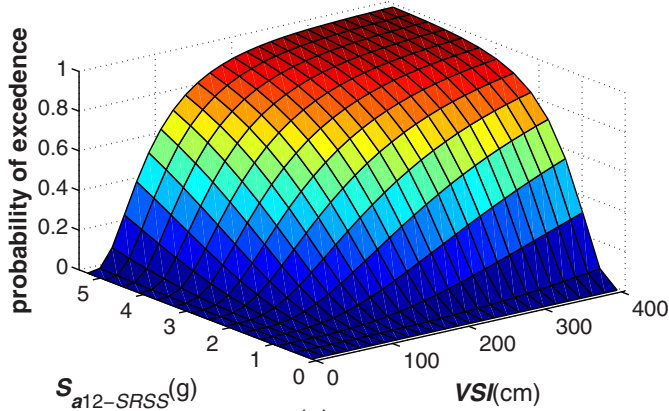

(a)

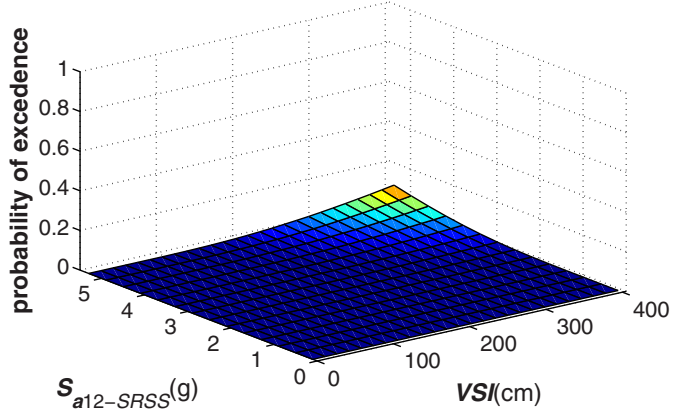

(c)

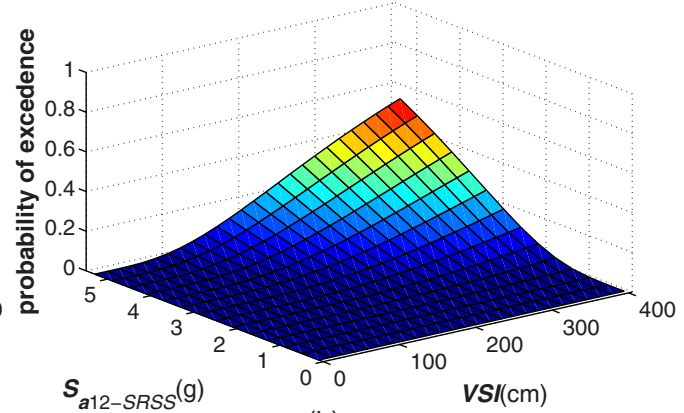

(b)

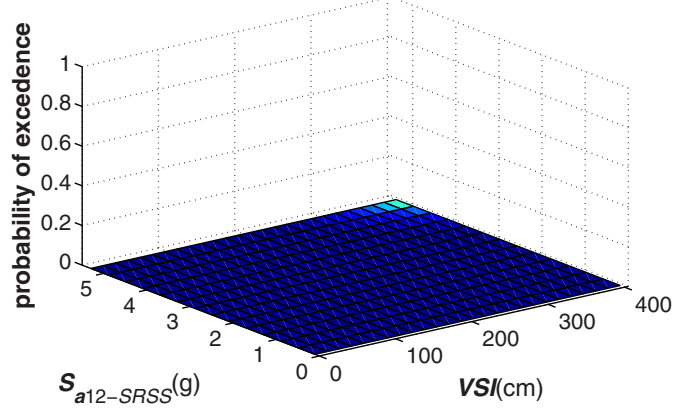

(d)

Figure 7. Fragility surfaces of fixed bearings at different damage states: (a) Slight damage; (b) moderate damage; (c) extensive damage; and (d) complete damage. 


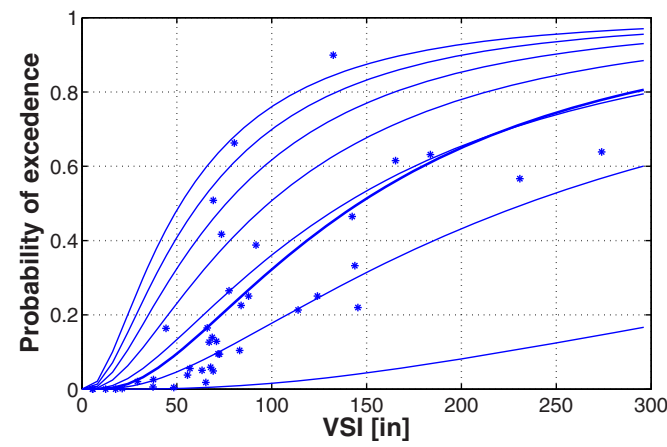

(a)

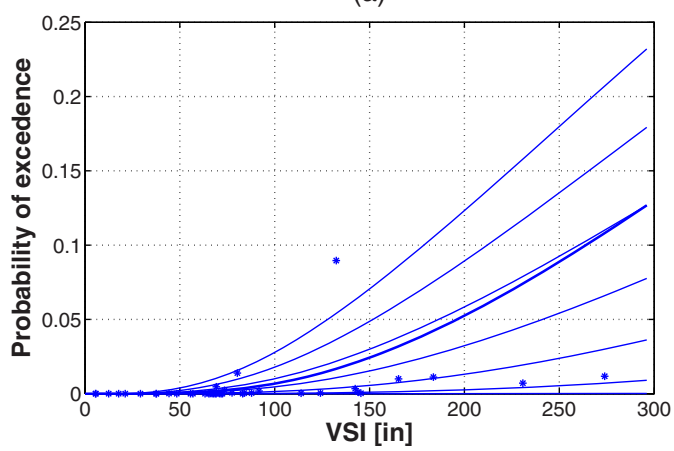

(c)

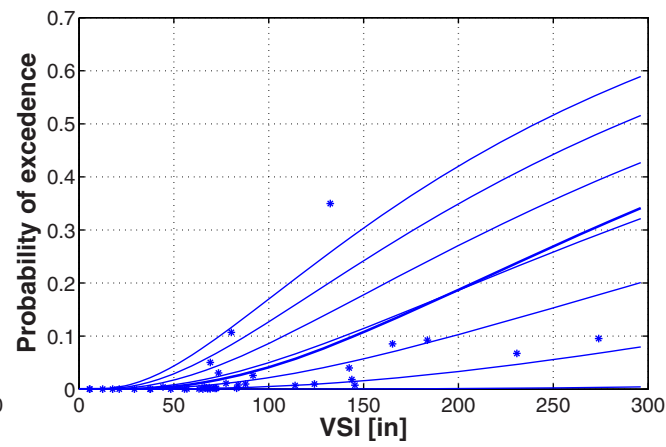

(b)

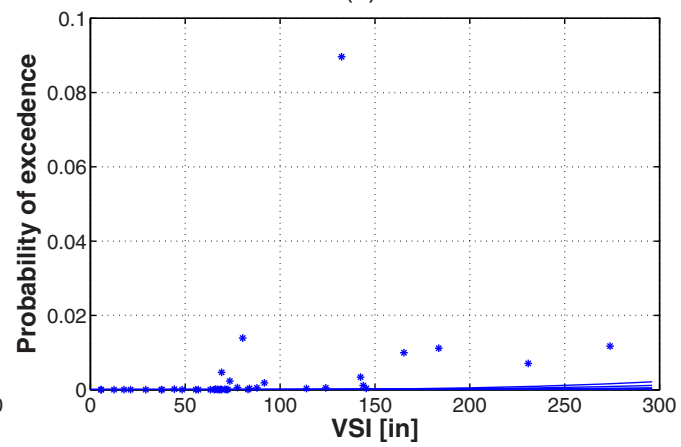

(d)

Figure 8. Comparison of fragility surfaces and fragility curves for fixed bearing at different damage states: (a) Slight damage; (b) moderate damage; (c) extensive damage; and (d) complete damage. Slices of the fragility surfaces are shown at increments of $S_{\text {a12-SRSS }}$ from bottom to top ranging from $0.2 \mathrm{~g}$ to $2.6 \mathrm{~g}$ at increments of $0.4 \mathrm{~g}$.

complete damage state, because the failure probabilities are very small, the results from the fragility surface and fragility curve show no differences. However, for other damage states, this figure implies that the failure probabilities caused by the earthquake obtained from the results of the fragility curve will be either underestimated or mostly overestimated depending on the amplitude of $S_{a 12-S R S S}$. For the forty earthquakes chosen in this study, 9 out of 40 of the earthquakes' failure probability are underestimated for the slight damage state and 5 out of 40 of the earthquakes' failure probabilities are underestimated for the moderate and extensive damage states, which means that in most cases, the failure probabilities obtained from the fragility curve are overestimated. This highlights the importance of using vector-valued PSDMs and fragility surfaces in the assessment of the bridge seismic vulnerability under the combined effect of vertical and horizontal ground motions.

\section{SUMMARY AND CONCLUSIONS}

In this study, a representative multi-span continuous steel (MSCS) girder bridge with liquefiable soil layers is used to investigate the effect of vertical ground motions (VGMs) on the component fragility of the coupled bridge-soil-foundation (CBSF) system. 
An advanced model of the CBSF system with a three-dimensional bridge superstructure, two-dimensional soil domain for keeping track of pore water pressures and the degradation of the soil stiffness after liquefaction, and one-dimensional set of $p-y, t-z$, and $q-z$ springs is built in OpenSees to incorporate the soil-structure interaction with liquefaction potential and to account for the seismic response under VGMs. Fragility curves for some key components influenced by VGMs are obtained. Fragility surfaces for the fixed bearings, which are the components that have the largest dispersion amongst the components considered, are also derived to improve the large dispersions that result from using only scalar intensity measures (IMs).

The results of probabilistic seismic demand analysis show that on the basis of efficiency, practicality and proficiency, $P G V$ is the optimal IM in predicting the seismic demands on components influenced by both horizontal ground motions (HGMs) and VGMs if only using a scalar IM from the horizontal motions. When considering the engineering demand parameters that are mostly influenced by the VGMs, like the negative bending moment of the bridge deck and the axial force of the column, the square-root-of-the-sum-of-squares of vertical spectral accelerations at the first and second vertical modes $\left(S_{a 12-S R S S}\right)$ of the CBSF system is the optimal IM. Moreover, unlike the horizontal only ground motions, the importance of including higher modes (in particular the second vertical mode) of the bridge when analyzing the seismic response under VGMs is found to be critical because the VGMs excite such higher vertical modes. This importance of considering higher modes is further underscored by the fact that $S_{\text {a12-SRSS }}$ is more efficient than spectral acceleration at the period of the first vertical mode $\left(S_{a l}\right)$ alone. In addition, when considering the effect of VGMs in probabilistic seismic demand analysis, the scalar IM from the HGMs alone will cause large dispersions for certain components of the CBSF system. Therefore, vector-valued IMs are recommended to predict the seismic demand of certain components (e.g., the fixed bearings) under the combined effect of vertical and horizontal ground motions. Results of this study show that the combination of velocity spectrum intensity $(V S I)$ and $S_{a 12-S R S S}$ is an optimal vector-valued set of IMs.

Results from the fragility analysis show that VGMs have a significant influence on the fragility of the fixed bearings. However, VGMs have little influence on the fragility of the expansion bearings as attributed to different vertical load distributions to each bearing type. Similarly, VGMs do not have any influence on the fragility of piles as measured by observable pile cap displacements because the axial forces of the piles are dominated by the rocking of the foundation and the superstructure caused by the HGMs. Whether VGMs have an impact on the columns depends on the design axial load ratio of the column. VGMs may also result in deck failures in the negative direction. Therefore, traditional bridge fragility analyses that neglect VGMs will underestimate the failure probability of certain components of the CBSF system. Furthermore, fragility surfaces give better estimates of the conditional failure probability than fragility curves. Using fragility curves based on the IM from HGMs alone may underestimate or overestimate the fragility of certain components depending on the characteristics of the vertical ground motion record. However, results show that the failure probabilities obtained from the fragility curve are overestimated in most cases. This study highlights that the inclusion of VGMs is important for the seismic fragility analysis of CBSF systems located in near fault regions and that using fragility surfaces leads to 
more accurate fragility predictions, which are essential in decision making about maintenance and retrofit programs.

Although the case study considers a representative MSCS bridge in the CEUS region, the findings of this paper may not be applicable to other geometric configurations and soil profiles, or other types of bridges. Further analysis is needed to investigate the influence of VGMs on the fragility of other configurations and types of bridges in the CEUS region, which is warranted given the results of this study, which highlight the significant impact of VGMs on the case study CBSF system.

\section{ACKNOWLEDGMENTS}

The authors gratefully acknowledge the support of this research by the National Science Foundation through Grants CMMI-0728040 and CMMI-0923493, as well as the Department of Civil and Environmental Engineering at Rice University. Any opinions, findings, and conclusions or recommendations expressed in this material are those of the authors and do not necessarily reflect the views of the National Science Foundation.

\section{REFERENCES}

Aygün, B., Dueñas-Osorio, L., Padgett, J. E., and DesRoches, R., 2011. Efficient longitudinal seismic fragility assessment of a multispan continuous steel bridge on liquefiable soils, Journal of Bridge Engineering 16, 93-107.

Ayyub, B. M., and Lai, K., 1989. Structural reliability assessment using latin hypercube sampling, Proceedings of ICOSSAR '89, the Fifth International Conference on Structural Safety and Reliability, San Francisco, CA.

Berry, M., and Eberhard, M. O., 2003. Performance models for flexural damage in reinforced concrete columns, available at http://nisee.berkeley.edu/elibrary/Text/1293029.

Berry, M. P. , and Eberhard, M. O., 2005. Practical performance model for bar buckling, Journal of Structural Engineering 131, 1060-1070.

Bradley, B. A., Cubrinovski, M., Dakhal, R. P., and MacRae, G., 2009. Intensity measures for the seismic response of pile foundations, Soil Dynamics and Earthquake Engineering 29, $1046-1058$.

Button, M. R., Cronin, C. J., and Mayes, R. L., 2002. Effect of vertical motions on seismic response of highway bridges, Journal of Structural Engineering 128, 1551-1564.

Cornell, C. A., Jalayer, F., Hamburger, R. O., and Foutch, D. A., 2002. Probabilistic basis for 2000 SAC Federal Emergency Management Agency steel moment frame guidelines, Journal of Structural Engineering 128, 526-533.

Elgamal, A., Yan, L., Yang, Z., and Conte, J. P., 2008. Three-dimensional seismic response of Humboldt Bay bridge-foundation-ground system, Journal of Structural Engineering 134, 1165-1176.

Elnashai, A. S., and Papazoglou, A. J., 1997. Procedure and spectra for analysis of RC structures subjected to strong vertical earthquake loads, Journal of Earthquake Engineering 1, 121-155.

Giovenale, P., Cornell, C. A., and Esteva, L., 2004. Comparing the adequacy of alternative ground motion intensity measures for the estimation of structural responses, Earthquake Engineering \& Structural Dynamics 33, 951-979. 
Kim, S. J., Holub, C. J., and Elnashai, A., 2011. Analytical assessment of the effect of vertical earthquake motion on RC bridge piers, Journal of Structural Engineering 137, 252-260.

Kramer, S. L., Arduino, P., and Shin, H. S., 2008. Using OpenSees for Performance-Based Evaluation of Bridges on Liquefiable Soils, PEER Report 2008/07, Pacific Earthquake Engineering Research Center, University of California, Berkeley.

Kunnath, S. K., Abrahamson, N., Chai, Y. H., Erduran, E., and Yilmaz, Z., 2008. Development of Guidelines for Incorporation of Vertical Ground Motion Effects in Seismic Design of Highway Bridges, A Technical Report Submitted to the California Department of Transportation under Contract 59A0434, Department of Civil Engineering, Structural Engineering, and Structural Mechanics, University of California, Davis.

Kunnath, S. K., Erduran, E., Chai, Y., and Yashinsky, M., 2008. Effect of near-fault vertical ground motions on seismic response of highway overcrossings, Journal of Bridge Engineering 13, 282-290.

Kwon, O.-S., and Elnashai, A. S., 2010. Fragility analysis of a highway over-crossing bridge with consideration of soil-structure interactions, Structure and Infrastructure Engineering 6, 159-178.

Ledezma, C., 2007. Performance-Based Earthquake Engineering Design Evaluation Procedure for Bridge Foundations Undergoing Liquefaction-Induced Lateral Spreading, Ph.D. Thesis, University of California, Berkeley.

Mackie, K., and Stojadinovic, B., 2001. Probabilistic seismic demand model for California highway bridges, Journal of Bridge Engineering 6, 468-481.

Mackie, K., and Stojadinovic, B., 2003. Seismic Demands for Performance-Based Design of Bridges, PEER 2003/16, Pacific Earthquake Engineering Research Center, University of Californita, Berkeley.

Mackie, K., and Stojadinovic, B., 2006. Seismic vulnerability of typical multiple-span California highway bridges, in Proceedings of the 5th National Seismic Conference on Bridges and Highways, 18-20 September 2006, San Francisco, CA.

Mander, J. B., and Kim, D. K., 1996. Response of Steel Bridge Bearings to the Reversed Cyclic Loading, Report No. NCEER 96-0014, National Center for Earthquake Engineering Research, $193 \mathrm{pp}$.

Mazza, F., and Vulcano, A., 2012. Effects of near-fault ground motions on the nonlinear dynamic response of base-isolated RC-framed buildings, Earthquake Engineering \& Structural Dynamics 41, 211-232.

Nielson, B. G., and DesRoches, R., 2007a. Analytical seismic fragility curves for typical bridges in the central and southeastern United States, Earthquake Spectra 23, 615-633.

Nielson, B. G., and DesRoches, R., 2007b. Seismic fragility methodology for highway bridges using a component level approach, Earthquake Engineering \& Structural Dynamics 36, 823-839.

Padgett, J. E., Nielson, B. G., and DesRoches, R., 2008. Selection of optimal intensity measures in probabilistic seismic demand models of highway bridge portfolios, Earthquake Engineering \& Structural Dynamics 37, 711-725.

Pan, Y., Agrawal, A. K., and Allampalli, S., 2010. Seismic fragility of multispan simply supported steel highway bridges in New York state, II: Fragility analysis, fragility curves, and fragility surfaces, Journal of Bridge Engineering 15, 462-472. 
Papazoglou, A. J., and Elnashai, A. S., 1996. Analytical and field evidence of the damaging effect of vertical earthquake ground motion, Earthquake Engineering \& Structural Dynamics 25, 1109-1137.

Saadeghvariri, M. A., and Foutch, D. A., 1991. Dynamic behaviour of R/C highway bridges under the combined effect of vertical and horizontal earthquake motions, Earthquake Engineering \& Structural Dynamics 20, 535-549.

Shafieezadeh, A., Ramanathan, K., Padgett, J. E., and DesRoches, R., 2012. Fractional order intensity measures for probabilistic seismic demand modeling applied to highway bridges, Earthquake Engineering \& Structural Dynamics 41, 391-409.

Veletzos, M., Restrepo, J., and Sieble, F., 2006. Seismic Response of Precast Segmental Bridge Superstructures, California Department of Transportation, Report Number SSRP-06/18, Department of Structural Engineering, University of California, San Diego, La Jolla, CA.

Wang, Z., Dueñas-Osorio, L., and Padgett, J. E., 2013. Seismic response of a bridge-soil-foundation system under the combined effect of vertical and horizontal ground motions, Earthquake Engineering \& Structural Dynamics 42, 545-564.

Zhang, J., Huo, Y., Brandenberg, S., and Kashighandi, P., 2008. Effects of structural characterizations on fragility functions of bridges subject to seismic shaking and lateral spreading, Earthquake Engineering and Engineering Vibration 7, 369-382.

Zhang, Y., 2006. Probabilistic Structural Seismic Performance Assessment Methodology and Application to an Actual Bridge-Foundation-Ground System, Ph.D. Thesis, University of California, San Diego.

(Received 16 October 2011; accepted 7 July 2012) 